Article

\title{
Procedure Negligence in Coastal Cargo: What Can Be Done to Reduce the Gap between Formal and Informal Aspects of Safety?
}

\author{
Tor-Olav Nævestad $^{1, *}$, Kristine Vedal Størkersen ${ }^{2}$ (1) and Ross O. Phillips ${ }^{1}$ \\ 1 Institute of Transport Economics, Gaustadalléen 21, NO-0349 Oslo, Norway; rph@toi.no \\ 2 NTNU Samfunnsforskning, NO-7491 Trondheim, Norway; kristine.vedal.storkersen@apertura.ntnu.no \\ * Correspondence: ton@toi.no; Tel.: +47-22-573800; Fax: +47-22-609200
}

Received: 7 July 2018; Accepted: 8 August 2018; Published: 14 August 2018

\begin{abstract}
Previous studies from the coastal cargo sector report of a considerable gap between formal and informal aspects of safety. Several maritime accident investigations point to this gap as an important contributory cause, indicating that risk increases when informal practices ignore or violate formal procedures. The main aims of this paper are therefore to examine the factors influencing procedure negligence in the coastal cargo sector, and to discuss how to reduce the gap between formal and informal aspects of safety. The study is based on quantitative survey results of 180 crewmembers and qualitative research interviews with 10 leading officers on cargo vessels sailing along the coast of Norway. Survey results indicate that procedure negligence is related to work pressure and demanding working conditions. It is also related to outcome measures like personal injuries and perceptions of risk and safety. A positive organizational safety culture is experienced by respondents reporting of less procedure negligence. Interview results indicate, for example, that formal procedures are ignored or violated because of issues like efficiency demands and low-quality procedures, and that procedures more often are followed when they are perceived as useful and timely. In this article, it is thus suggested that a positive safety culture includes an alignment of formal and informal aspects of safety, which requires time to comply with practical procedures. Interviewees suggest that appropriate procedures are: (1) developed by the users, (2) continuously improved, (3) simplified, and (4) supervised by local expertise instead of general experts.
\end{abstract}

Keywords: procedure negligence; maritime sector; safety culture; ISM-code; coastal cargo

\section{Introduction}

Seafaring, which is central to world trade [1], is still termed one of the most hazardous occupations, even though safety improvements have led to a significant decrease in the mortality rates of seafarers in recent decades [2]. There were on average 15 killed and 424 injured annually on Norwegian ships in the period 2004-2013, and cargo ships have the highest average number of deaths and serious injuries in Norway [3]. and across Europe [4]. There is thus a considerable safety potential in improving the safety on cargo vessels.

The safety improvement in the maritime sector in recent years should be attributed to a range of different factors (e.g., technical, legal, structural, cultural), and part of the improvement has been attributed to the International Safety Management (ISM) code. Studies indicate that the requirements of the ISM code have the potential to foster a positive safety culture on board vessels [5-7]. The ISM code was made mandatory in 1998 by the International Maritime Organization. The code requires the shipping companies to implement safety management systems (SMS), which are comprised of formalized descriptions of work and hazard management activities, e.g., procedures, reporting 
systems, hazard identification, risk mitigation, etc. [8]. Research from the coastal cargo sector in Norway indicates, however, that $40 \%$ of the respondents violate procedures to get the job done, especially because of efficiency demands [9].

The commonality of procedure violations indicates a considerable gap between formal and informal aspects of safety; which may impede the effective functioning of SMS and a positive safety culture. On one hand, we have formal aspects of safety, or safety structure, which may refer to the SMS requirements of the ISM code-formalized descriptions of "how things should be done". Informal aspects of safety, one the other hand, are related to safety culture, and refers to "how things are actually done", as indicated by shared work practices, shared ways of thinking, managers' and employees' commitment for safety etc. [10,11].

The main aims of this paper are therefore to examine the factors influencing procedure negligence in the coastal cargo sector, and to discuss how to reduce the gap between formal and informal aspects of safety. Procedure negligence refers both to intentional negligence (violations) and unintentional negligence, which for instance may be due to lacking knowledge about procedures. Negligence may both be individual and collective. As we will see below, collective procedure negligence may be related to safety culture, if the collective negligence represent shared ways of acting on board (cf. our definition of safety culture). It is important to develop knowledge about the gap between formal and informal safety aspects of safety, to be able to successfully implement SMS. High shares of procedure violations or collectively neglected procedures may be a symptom of a safety structure which is not functioning properly, and a negative safety culture.

The quantitative survey data that the present study is based on, was originally collected in another project, which is presented in two reports $[12,13]$. Additionally, a scientific article, focusing especially on organizational safety culture [14], has also been published based on the survey data. The former study [12] compared safety on nationally flagged (NOR) vessels with vessels flying flags of convenience, focusing on e.g., national safety culture, communication, working conditions, fatigue and implementation and enforcement of international rules. In the present paper, we only include survey data from the nationally flagged vessel respondents $(N=180)$ from the sample in the original study [12], to be able to study organizational safety without the possible confounding effect of crew nationality or vessel flag (see also: [13]).

\section{Previous Research}

\subsection{Formal and Informal Aspects of Safety}

Safety culture includes safety-relevant aspects of the larger organizational culture [15]. We define safety culture as shared and safety relevant ways of thinking or acting that are (re)created through the joint negotiation of people in social settings [11]. The majority of studies of safety culture point to senior managers' commitment to safety as the most crucial aspect [16-19].

Just as we define safety culture as aspects of culture in organizations that are relevant to safety [15], we define safety structure as safety-relevant aspects of organizational structure. Organizational structure refers to the way tasks in an organization are divided, how work flows, how this flow is coordinated and the forces and mechanisms that allow this coordination to happen [20]. According to McShane and Travaglione [20], coordination can be achieved by: (1) informal communication; (2) formal hierarchy, involving direct control; and (3) standardization, with formal instructions (standardization/specification of tasks), goals (standardization of outcomes), or training (standardization of knowledge).

\subsection{Causes of Procedure Negligence}

Numerous accident investigations point to a discrepancy between formal and informal aspects of safety to explain why accidents come about (cf. $[3,11]$ ). The discrepancy between formal and informal aspects of safety is also referred to as practical drift [21]. In the present paper, we suggest that 
a high level of procedure negligence-violating or overlooking the rules-may indicate a discrepancy between formal and informal aspects of safety.

\subsection{Human Error}

Human errors may cause (or be a symptom of) a discrepancy between formal and informal aspects of safety. James Reason's [22] taxonomy of human error is a commonly used analytical scheme to discern between different forms of errors. He discerns between (a) slips, (b) lapses, (c) mistakes, (d) violations. Slips are the most prevalent type of errors, referring to actions guided by a correct plan or intention, but which failed to produce the expected outcome. These may refer to situations where procedures were followed, but perhaps procedures were inappropriate, or wrong procedures were used. Lapses are missed actions or omissions, e.g., because of inattention or memory failure. These may refer to situations where procedures not are used, as they were forgotten, or because they are unknown, or not used in practice ("sleeping rules"). A mistake is an action which is carried out as intended, but which was guided by an inappropriate plan. These may refer to situations where wrong procedures were used. Violations are actions deviating from accepted rules, standards or procedures. Violations may be carried out either intentionally or unintentionally [22]. As we can see, lapses and violations involve procedure negligence, since the formal procedures are not used, ignored, or violated.

\subsection{Organizational Causes}

Poor safety culture. The importance given to the discrepancy between formal and informal aspects of safety in accident investigations indicates that although organizations' formal descriptions of how to achieve safety; the 'safety structure' may seem to be well functioning, it is the implementation of these principles into the daily work practices; 'safety culture', which is decisive for safety. Thus, procedure violations and sleeping rules may be an indication of a poor safety culture. 'Sleeping rules'; situations where rules are not used in practice by the crew may indicate collective practices, and may thus be described as safety culture, according to our definition.

In 12 of the 48 AIBN reports studied by Nævestad et al. [3], it is found that although procedures, risk assessments or safety management systems (SMS) may be in accordance with regulations, these are not adhered to in practice; a finding that might suggest that the safety culture on board the vessel or in the shipping company is not satisfactory. In some cases, vessels violate safety rules of the shipping company. In other cases, work groups (or individuals) may violate safety rules. In both cases, the work practices of groups are not in adherence with procedures.

Professional identity. Lappalainen et al. [5] study the introduction of the ISM code for international shipping, based on a literature review of previous studies of the ISM code, and 94 interviews conducted with shipping companies, mariners, and other maritime stakeholders in the Finnish shipping industry in 2008-2009. The study concludes that the introduction of the ISM code led to an improved safety level, and an improved safety culture. Lappalainen et al. [5] note, however, that the ISM-code faced employee resistance in the early implementation phase, as seafarers felt that their professional pride was discredited. They note that in the early ISM-code period, seafarers regarded the safety manuals as useless, as they considered themselves professionals. The resistance from such sub-cultures waned as systems became more user-friendly, and as the 'old generation' of seafarers was replaced.

Competition and efficiency demands. Størkersen et al. [9] find that efficiency demands are the most important reason procedures are violated to get the job done. Maritime accident investigations and studies show that leading bridge officers and other crew members must constantly balance considerations related to economy and safety, and shipping companies' transport buyers to a considerable degree define the conditions for safety [23] (see also [24,25]).

Working conditions and work pressure. Størkersen et al. [9] studied 10 coastal cargo vessels sailing along the coast of Norway by means of qualitative interviews, field work, and surveys. This report especially points to fatigue, substantial workload, and alienation, suggesting that these factors could increase the probability of operational errors. As noted, this study found that a third of the respondents 
answered that they put themselves in danger to get the job done, while about $40 \%$ violate procedures to get the job done, especially because of efficiency demands. Størkersen et al. [9] refer to "sleeping rules" as one of the main findings of their study. This means that some rules are followed on board while other are ignored.

Company size. The reports of the Norwegian Maritime Accident Investigation Board Norway studied by Nævestad et al. [3] often seem to find that small companies involved in accidents have underdeveloped and/or unclear organizational structures. In accordance with this, research indicates that management using formal measures (e.g., procedures, predefined safety roles) is less important than informal modes of management (e.g., culture, attitudes) in smaller companies [26]. This research also indicates that the smaller companies have less resources (applying to e.g., personnel, money, and expertise), compared to larger companies. Moreover, we may hypothesize that small companies, e.g., with a handful of employees are less reliant on formal systems for standardizing (e.g., training, procedures) and coordinating behavior. We may hypothesize that much of this can be done informally in smaller companies, through direct personal contact between managers and employees. As a consequence, formal safety management systems may hypothetically be perceived as less relevant in smaller companies.

Low degree of ownership to the procedures. Previous research also indicates that the high rate of violations also may be due to a low degree of crew ownership to the procedures. It is difficult to assess the importance of this factor, as it may both be a symptom, and a cause. As small companies often are short of legal competence in-house, but still must comply with safety management regulation, many rely on consultants to translate the regulations into practice [27]. Safety management systems developed as inexpensively as possible with the objective to be found flawless by any auditor, often become standardized and complex with more procedures and reporting than necessary for a particular company's activities. They result in proceduralization and bureaucracy that may marginalize practical safety work [27-29] and leave the seafarers to avoid compliance and dislike the safety management systems $[6,30,31]$. Finally, violations and sleeping rules may also be a result of the fact that procedures are inappropriate for other reasons, e.g., as it is difficult to regulate the work activities in question, as the nature of work activities has changed since the procedures were developed, etc.

\section{Methodological Approach}

\subsection{Interviews}

The qualitative data material consists of interviews with ten ship officers from seven different Norwegian ship-owning companies. All 10 interviewees are ship officers and educated navigators. Eight work as captains or mates on their cargo vessel. Two now work in the office as managers. One is partly captain and partly ship-owner, which is quite common in the Norwegian coastal cargo industry. See Section 5.3 for reflections about the number of interviewees.

Their vessels transport dry bulk cargo, general cargo, fodder for fish farms, or live fish. Thus, the interviews give perspectives from different parts of the Norwegian coastal cargo sector. The ship officers volunteered to be interviewed after information about the project from the researchers through their companies to all their seafarers. In further studies, one should work to include voices from groups such as ratings and machine chiefs.

We conducted eight semi structured research interviews of $1-2 \mathrm{~h}$. Two of the interviews involved two interviewees, and 10 people were interviewed in total. The interviews were based on an interview guide constructed to explore Norwegian cargo safety culture and its relations to organizational and societal aspects. Among the subjects asked about were conditions for work and rest (manning, watch-keeping, tasks, etc.), perceptions of safety, leadership, team culture, safety management, safety regulation, and organizational and national values. Six interviews were phone interviews, with one researcher talking to one ship officer. Two interviews were conducted on the vessel, each with one researcher talking to two ship officers. One of these interviews was recorded and transcribed in 
verbatim. For all interviews, detailed and anonymized research notes were written. Categorization and pattern-analysis was performed manually. The quotes in Section 4 are direct citations of the ship officers, from the research notes and transcriptions.

\subsection{Survey}

\subsubsection{Recruitment of Respondents}

All the respondents participating in the quantitative survey work on Norwegian registered vessels, operated by shipping companies in Norway. We recruited respondents through our contact with an employer association, which organize Norwegian based shipping companies. Over 150 shipping companies with approximately 300 vessels were members of this association at the time of the survey. The employer association submitted our web links to the questionnaires to all members, together with our introductory text, providing the objectives of the survey, underlining that the surveys were confidential. The shipping companies were asked to distribute the survey to all employees working on ships.

It may be discussed whether recruiting respondents through the companies own systems may influence their answers in any way, and whether it involves any ethical challenges. It is, for instance, hypothetically possible that respondents might feel 'forced to participate', and thus their answers are not totally impartial, since they might feel the stress from the company to fulfill the need for the research that the company has approved. We do not have reasons to believe that such processes have influenced our data. First, in our contact with the employer organization of the shipping companies, we underlined that participation was voluntary and anonymous, and we also provided information texts about this which were forwarded to shipping companies and potential respondents along with survey links. Some companies and respondents declined to participate in our survey. Second, the focus in the survey and the analysis is not on specific shipping companies, making it unlikely that respondents' answers are shaped by a perceived obligation to shed favorable light on their company. Third, the results of the survey present the same challenges related to working conditions and framework conditions that are found in the interview results and in previous research (e.g., [9]). This indicates that it seems unlikely that respondents' answers have been influenced substantially by the discussed methodological and ethical challenges.

\subsubsection{Sample}

In Table 1, we provide the key features of respondents related to demographic variables and respondents' vessels.

Table 1. Key features of the 180 respondents, related to demographic variables and respondents' vessels (\%).

\begin{tabular}{ccccccc}
\hline & Age Group & Position & Experience & Vessel Type & $\begin{array}{c}\text { Year the Vessel } \\
\text { Was Built }\end{array}$ & Vessel Size \\
\hline \multirow{2}{*}{1} & $\begin{array}{c}\text { Younger than } \\
31 \text { years }\end{array}$ & Captain & $\begin{array}{c}\text { Less than } \\
\text { one year }\end{array}$ & Bulk & Before 1980 & $<500$ DWT \\
\cline { 2 - 7 } & $31 \%$ & $28 \%$ & $4 \%$ & $34 \%$ & $16 \%$ & $19 \%$ \\
\hline \multirow{2}{*}{2} & $31-40$ & Deck officer & $1-3$ years & General cargo & $1980-1985$ & $500-3000$ DWT \\
\cline { 2 - 7 } & $17 \%$ & $24 \%$ & $9 \%$ & $14 \%$ & $8 \%$ & $79 \%$ \\
\hline \multirow{2}{*}{3} & $41-50$ & Deck crew & $4-10$ years & Tank vessel & $1986-1991$ & $>3000$ DWT \\
\cline { 2 - 7 } & $23 \%$ & $20 \%$ & $24 \%$ & $4 \%$ & $3 \%$ & $2 \%$ \\
\hline \multirow{2}{*}{5} & $51-60$ & Chief engineer & $11-15$ years & Live fish carrier & $1992-1997$ & - \\
\cline { 2 - 7 } & $23 \%$ & $7 \%$ & $7 \%$ & $34 \%$ & $16 \%$ & - \\
\hline
\end{tabular}


Table 1. Cont.

\begin{tabular}{ccccccc}
\hline & Age Group & Position & Experience & Vessel Type & $\begin{array}{c}\text { Year the Vessel } \\
\text { Was Built }\end{array}$ & Vessel Size \\
\hline \multirow{2}{*}{7} & - & Engine crew & - & $\begin{array}{c}\text { Anchor } \\
\text { handling vessel }\end{array}$ & $2004-2009$ & - \\
\cline { 2 - 7 } & - & $4 \%$ & - & $1 \%$ & $23 \%$ & - \\
\hline \multirow{2}{*}{8} & - & Catering & - & $\begin{array}{c}\text { Fish farming } \\
\text { vessel }\end{array}$ & $2010-2015$ & - \\
\cline { 2 - 7 } & - & $5 \%$ & - & $6 \%$ & $21 \%$ & - \\
\hline 9 & - & Apprentice & - & Other & Before 1980 & - \\
\hline \multirow{2}{*}{10} & - & $9 \%$ & - & $5 \%$ & $14 \%$ & - \\
\cline { 2 - 7 } & - & Other & - & & - & - \\
\hline Total & $100 \%$ & $100 \%$ & $100 \%$ & $100 \%$ & $100 \%$ & $100 \%$ \\
\hline
\end{tabular}

There are only two women in the sample, and therefore we do not show results for gender. We do not show results for the nationality of the seafarers, as we only focus on nationally flagged (NOR) vessels, with a low proportion of foreign employees. Among the respondents, $7 \%$ were from other Nordic countries (i.e., not Norway), $1 \%$ were from other Western European countries and $2 \%$ from Central/Eastern European countries. Four percent of the respondents defined their line of transport as tank transport. The tank transport that these respondents are involved in is fish products and not dangerous goods, e.g., oil or gas.

\subsubsection{Survey Measures}

The surveys included a total of 80 questions on the following themes:

1. Background variables related to respondents: 7 questions.

2. Organizational safety culture: 18 questions.

3. Nationality, language, communication, and safety: 9 questions.

4. Manning level and fatigue: 19 questions.

5. Economy, efficiency, competition, and safety: 5 questions.

6. Vessel characteristics, technology, and safety: 6 questions.

7. Port calls and time pressure: 3 questions.

8. Competence, nationality, and safety: 3 questions.

9. National safety culture: 7 questions.

10. Safety outcomes: 6 questions.

11. Risk analyses and procedures: 4 questions.

See Appendix A for a detailed description of survey measures. The present report only focuses on the questions that may shed light on the study aims.

\subsubsection{Analysis of Quantitative Data}

Cronbach's alpha. Several multiple item measures were created for the purpose of this study. Internal consistency was assessed using Cronbach's Alpha. When measuring different safety aspects, we create indexes, comprised of several questions We assume that respondents' answers to questions which are supposed to measure the same aspect correlate, meaning that it is likely that a person who agrees with one question also agrees with the other questions that make up the aspect, for instance related to safety attitudes or behaviors. We assume this when we make indexes, and Cronbach's Alpha provides a way of testing this assumption, as it measures the correlation among responses on the index. The value varies between 0 and 1 . A Cronbach's Alpha over 0.9 is very high, between 0.9 and 0.8 is 
good, between 0.8 and 0.7 is acceptable, between 0.7 and 0.6 is questionable, a score between 0.5 and 0.6 is poor and a score below 0.5 is unacceptable.

Significance tests of means. We use one-way ANOVA tests, in our comparisons of the mean scores of different groups. These tests compare whether the mean scores are equal (the null hypothesis) or (significantly) different.

Pearson's $r$. When examining bivariate relationships or the possible correlation between two variables, we use the Pearson's $r$ or the 'Pearson product-moment correlation coefficient'. Pearson's $r$ provides a measure of the linear correlation between two variables. It provides a value between +1 and -1 inclusive, where 1 involves a total positive correlation, 0 is no correlation, and -1 is a total negative correlation.

Chi-square. We also use chi-square tests to compare groups' scores on particular variables, if we for instance cannot compare means due to the variables' level of measurement. The chi square test tests whether the actual distribution of groups on a variable is statistically significant different from a coincidental distribution, or an independent normally distributed sample.

Regression Analyses. We provide a regression analysis in the present paper, examining variables predicting respondents' answer on the index measuring procedure negligence. Hierarchical, linear regression analysis was used, where independent variables are included in successive steps. We apply the most basic independent variables (e.g., age, sex, vessel type, position) first before applying the other more conceptual independent variables (e.g., working conditions, safety culture). Of course, we cannot conclude about causality, as this is a cross-sectional and correlational study. Nevertheless, we use the term predict when describing the regression analyses.

\section{Results}

This section includes survey and interview results of procedure negligence and causes of procedure negligence, in addition to interview results about how to close the gap between informal and formal safety management.

\subsection{Procedure Negligence}

\subsubsection{Survey Results}

In the survey, the 180 respondents rated their agreement with three statements about procedure negligence:

- Violation of procedures seldom has consequences (53\% disagree, $24 \%$ neither $/$ nor, $23 \%$ agree)

- The competition between shipping companies means that we sometimes have to violate safety procedures ( $77 \%$ disagree, $12 \%$ neither $/$ nor, $11 \%$ agree)

- I never use written procedures in the work I perform on board (69\% disagree, $17 \%$ neither $/$ nor, $15 \%$ agree)

These three statements were combined into an index. Table 2 provides average scores for different groups on this index measuring procedure negligence. The minimum value is 3 (totally disagree) and the maximum value is 15 (totally agree). The average score on the index is 6.3 points. 
Table 2. Means on the index based on three statements measuring procedure negligence. The minimum value is 3 (totally disagree) and the maximum value is 15 (totally agree).

\begin{tabular}{|c|c|c|c|c|c|c|c|c|}
\hline Value & $\begin{array}{l}\text { Age } \\
\text { Group }\end{array}$ & $\begin{array}{l}\text { Vessel } \\
\text { Type }\end{array}$ & $\begin{array}{l}\text { Position/Line } \\
\text { of Work }\end{array}$ & $\begin{array}{l}\text { Port Calls } \\
\text { Per Week }\end{array}$ & $\begin{array}{c}\text { Manning } \\
\text { Level }\end{array}$ & $\begin{array}{l}\text { Demanding } \\
\text { Working } \\
\text { Conditions }\end{array}$ & $\begin{array}{c}\text { Work } \\
\text { Pressure }\end{array}$ & $\begin{array}{c}\text { Org. } \\
\text { Safety } \\
\text { Culture }\end{array}$ \\
\hline \multirow[t]{2}{*}{1} & $\begin{array}{l}\text { Younger } \\
\text { than } \\
31 \text { years }\end{array}$ & Bulk & Captain & $1-3$ & 1-2 people & $3-4$ points & $\begin{array}{c}\text { Totally } \\
\text { disagree }\end{array}$ & $18-69$ \\
\hline & 6.4 & 5.9 & 6.5 & 6.6 & - & 4.8 & 4.9 & 8.8 \\
\hline \multirow[t]{2}{*}{2} & $31-40$ & $\begin{array}{c}\text { General } \\
\text { cargo }\end{array}$ & $\begin{array}{c}\text { Deck } \\
\text { personnel }\end{array}$ & $4-6$ & 3-4 people & $5-6$ points & $\begin{array}{c}\text { Disagree } \\
\text { somewhat }\end{array}$ & $70-75$ \\
\hline & 7.3 & 6.6 & 6.4 & 5.2 & 7.6 & 6 & 5.9 & 8.1 \\
\hline \multirow[t]{2}{*}{3} & $41-50$ & $\begin{array}{c}\text { Tank } \\
\text { vessel }\end{array}$ & $\begin{array}{l}\text { Engine } \\
\text { personnel }\end{array}$ & $7-9$ & 5-6 people & $7-8$ points & Neither/nor & $76-80$ \\
\hline & 6.3 & 6.3 & 6 & 7.1 & 6.3 & 6.8 & 8.7 & 6 \\
\hline \multirow[t]{2}{*}{4} & $51-60$ & $\begin{array}{c}\text { Live fish } \\
\text { carrier }\end{array}$ & Other & $10-12$ & 7-8 people & 9-10 points & $\begin{array}{c}\text { Agree } \\
\text { Somewhat }\end{array}$ & $81-85$ \\
\hline & 5.6 & 6.6 & 6.1 & 7 & 5.9 & 7.6 & 8.7 & 5.9 \\
\hline \multirow[t]{2}{*}{5} & $\begin{array}{c}\text { Older } \\
\text { than } \\
60 \text { years }\end{array}$ & Other & - & $13-15$ & 9-10 people & $11-12$ points & $\begin{array}{l}\text { Totally } \\
\text { agree }\end{array}$ & $86-90$ \\
\hline & 6.1 & 6.6 & - & 5.8 & - & 7.8 & 11.6 & 4.9 \\
\hline \multirow{2}{*}{6} & - & - & - & $>15$ & 11-12 people & 13-21 points & - & - \\
\hline & - & - & - & 6.7 & - & 10 & - & - \\
\hline$p$ value & 0.202 & 0.698 & 0.846 & 0.053 & 0.208 & 0.000 & 0.000 & 0.000 \\
\hline
\end{tabular}

Table 2 indicates a relationship between demanding working conditions and procedure negligence. The more demanding working conditions, the more procedure negligence. The same applies to work pressure.

Table 2 also indicates a relationship between organizational safety culture and procedure negligence. A high organizational safety culture score gives a low score on the index; i.e., fewer procedure violations and more procedure use.

\subsubsection{Interviewees' Experience of Procedure Negligence}

The interviewed seafarers underline that most of the work is done safely and according to procedures. Still, procedure negligence happens frequently. Formal procedures are violated out of necessity, the seafarers state: when procedures do not fit the situation, or the vessel do not have time or manning to comply. Lapses are also common, where the seafarers do not know the procedure or forget it. Before, it was normal to forget to use hard hat or life vest, but this has decreased.

Most of the interviewees emphasize situations where a procedure is not practically doable, especially because it takes too much time. 'Short cuts' or 'calculated risks' to work efficiently seem to be a regular part of work among all interviewees in the study. Everyone underlines that they have to be efficient for their company to be in business. If they miss a port call or some cargo has to stay, they miss out on essential earnings. The financial situation and competition in Norwegian and global transport is present in the seafarers' daily work.

We take short cuts; we don't have manning to get everything formally right. As we see it, we have done it a thousand times, and it has never been a problem.

Captain, general cargo vessel

Violation of procedures is normal where the crew does not see any risk, and if there are some risk, but compliance would take too much time. The following situation was mentioned as an example of a situation with some risk, but not enough for it to be worth following plundering procedures: 
If a hydraulic hose snaps on the unloading crane while we lie working, we might need to change it in an unfavorable situation. Bad weather and darkness. We need to climb. It can't be ideal conditions, and we will take a calculated risk. And it's not always we can finish. We could take better measures. [... ] In a perfect situation you'd stop and sail to quay and rent a lift. [ ... ] You don't do that.

Mate, fodder vessel

A more common scenario is that the crew works according to procedures, but without doing the mandatory preparations, such as risk analysis or paperwork. Some of the seafarers are certain that they would have ended up doing the exact same thing if they did an analysis beforehand.

If you're to do a crane lift, you just do it, without thinking more about it. Ideally it should've been analyzed, but the conclusion's that we did it the same way, because it's only one way to do it.

Captain, general cargo vessel

Some coastal cargo seafarers compared their situation with the oil and gas industry, suggesting that the offshore installations traditionally have had "too large manning and too extensive safety management systems". As a consequence, some interviewees suggested that as offshore workers are "not used to doing anything without checklists, they don't get anything done".

Many formal procedures are seen as unfitting for the coastal vessels' activity and manning. Several of the interviewees describe that persons responsible for too many tasks cannot do all, but still tick boxes in the system to "document" that they did everything every week. This can go on at every shift. An interviewed seafarer reflects over whether this leads to good safety culture:

ISM isn't just positive. Is it good safety culture? I don't know. It's often lack of time, plus the fact that you get sick of it. For instance, it says you're to test the emergency radio every day. That's something you just don't bother.

Mate, bulk vessel

\subsection{Causes of Procedure Negligence}

\subsubsection{Survey Results}

Table 3 provides results from a hierarchical, linear regression analysis, where independent variables are included to examine factors predicting the 180 respondents' score on the procedure negligence index. The dependent variable varies between 3 (totally disagree) and 15 (totally agree).

Table 3. Linear. Dependent variable: 'procedure negligence index'. The dependent variable varies between 3 (totally disagree) and 15 (totally agree). Standardized beta coefficients.

\begin{tabular}{|c|c|c|c|c|c|c|c|c|}
\hline Variables & Step 1 & Step 2 & Step 3 & Step 4 & Step 5 & Step 6 & Step 7 & Step 8 \\
\hline Age group & $-0.140 *$ & $-0.138 *$ & -0.131 * & -0.114 & -0.122 & -0.079 & -0.027 & 0.012 \\
\hline Vessel type $($ Other $=1$, Tank vessel $=2$ ) & & -0.033 & -0.038 & -0.063 & -0.081 & -0.077 & -0.086 & $-0.113 *$ \\
\hline Port calls & & & & $0.157^{* *}$ & 0.149 * & 0.088 & 0.066 & 0.026 \\
\hline Manning level & & & & & -0.103 & -0.015 & 0.031 & 0.042 \\
\hline Work pressure & & & & & & & & $0.492 * * *$ \\
\hline Adjusted $R^{2}$ & 0.014 & 0.009 & 0.004 & 0.023 & 0.027 & 0.215 & 0.321 & 0.468 \\
\hline
\end{tabular}


First, we see that age group contributes significantly and negatively to respondents' procedure negligence in Steps 1-3 indicating that the older respondents are less likely to agree with the questions concerning procedure negligence. This variable ceases to be significant when we take in the weekly number of port calls in Step 4.

The positive contribution of port calls indicates that a high work load (many port calls) may lead to more procedure negligence. Port calls contributes significantly in Steps 4-5 until organizational safety culture is included in Step 6.

The effect of organizational safety culture is strong and negative, and it is significant at the $1 \%$ level in Steps 6 and 7, until work pressure is included in the analyses. As the contribution of safety culture is reduced in Step 8, we may also conclude that it seems that safety culture and work pressure are strongly related.

In Step 8, we see that work pressure provides the strongest contribution to respondents' procedure negligence, followed by demanding working conditions and safety culture.

When organizational safety culture was taken into the analysis in Step 6, the Adjusted $R^{2}$ value rose from 0.027 to 0.215 indicating that the variables in the Step 6 (primarily safety culture) explain about $21 \%$ of the variation in the dependent variable. The Adjusted $R^{2}$ value in Step 8 is 0.468 , indicating that the variables in the Step 8 explains about $47 \%$ of the variation in the dependent variable.

\subsubsection{Interviewees' Experience of Work Pressure}

The ship officers tell us that they always do the tasks as safe as possible-at the same time as being efficient. This is seldom talked about as demanded by their company, but rather as an internal criterion that must be handled by every seafarer that is to do a good job. Still, the interviews indicate that some perceptions about pressure to go through with risky operations and to work while tired. The seafarers all agree that some operations cannot be accomplished, but their doubts and perception of pressure to continue operations vary.

Sometimes you feel it. Maybe when you're approaching the quay, "will this work or not", but usually it works okay. You have to use your common sense, and know your limitations. You can lie at sea until the conditions are better. Even if someone stands at shore and waits, they just have to wait. But you do feel it. But in the end, you don't care, even though you think about it afterwards.

Captain, bulk vessel

Another type of work pressure is working when fatigued. Also, this is mostly talked about as something that all seafarers experience and need to handle if they are to do their job.

You have chosen an occupation and it's been like this since I started at sea. Since I started as a deck boy. Everyone had to chip in when we loaded, and we could relax when the ship was at sea. It's a culture that ... It's not possible to change a culture that's been there forever. When the load's ready: "Oh, no, I have to sleep ten hours, I can't work", right. I will not make money and the company will not make money. Then I'd have to quit. I'd have to go home and stay on welfare, that's next.

Captain, bulk vessel

Both the weather and organizational conditions contribute to the lack of sleep and rest. The companies are in charge of manning, watch-keeping schedules and sailing schedules to a degree, but most of the seafarers rather talk about the tiredness as 'how it is' for seafarers.

Particularly on timber runs, some ports are close to each other. You get two-three hours on the pillow before it's up again. And we load for four-five hours and continue. Four-five hours to next port, and loading again. And maybe you have four ports like that after each other. Then you'll be tired when you're finished. 


\section{Captain, bulk vessel}

The work pressure is a mix of conditions stemming from employers, customers, the industry and also the seafarers themselves. They take responsibility for their company to stay in business and themselves to keep their job. The coastal cargo companies are in competition with other types of transportation, with each other and with vessels of different flags/conditions. It is a buyer's market. Some say that the customers are becoming interested in safety on the vessels, since they want the cargo to come in safely and according to regulations. Still, most emphasize that the buyers focus on price rates.

It's awful, just prices. It's nothing to ask about, just price and price and price. They don't look at what's in the dock, just as long as it floats it's okay. [If there were more audits, something could change.] But it's price. If they get someone to transport the cargo, they'd run with it. It's just prices. That's how all cargo transport is. Also, trucks-they're also out in the cold.

Captain, bulk vessel

\subsubsection{Interviewees' Experience of Impracticable Procedures}

All Norwegian commercial vessels and their ship-owning companies must have safety management systems, due to the ISM code. Some seafarers tell that the safety management systems have improved safety and safety culture over the years, because it has made them consider risk and talk about how work can be performed in a safe manner.

It's pretty good now. HSE meetings ... I don't think any industry in the world focus more on safety. It's almost like you can't go to the loo without asking for replacement. The risk's if it becomes too much. But it's pretty good now.

Mate, live fish carrier

Yet, all interviewees talk negatively about their safety management systems. They are too large, too complex, and with procedures that cannot be complied with. One of the interviewed seafarers notice that it is dangerous with too many procedures. Now, no one has oversight, and some tasks might be neglected over a long time. Some say that they used to have practical procedures that everyone on board knew by heart, but that the procedures now have grown into dozens of books and that they have lost the feeling of control.

The problem is that the ISM-system's too big and extensive for the ordinary man to take the trouble to get to know it. So, it's usually the ship management that knows what it's about. This is an overstatement, because most [crewmembers] know the basics, but not more than that.

Mate, bulk vessel

Some seafarers' descriptions indicate that it is common for the ship-owner companies to buy safety management systems complete with procedures. The procedures are made for other vessels, mostly bigger and with other activities. This makes seafarers believe that the formal procedures need to be impracticable and unusable.

It's normal to buy a system and start to use it immediately. That leads to frustration and theater acting. And people loose motivation. [ ... ] It's not sure the company was so thorough. They buy a commodity, and it was made for an offshore vessel, and it's us that get the requirements. That's the tendency: that we get that requirement, and we don't have a system and training that harmonizes.

Mate, fodder vessel 


\subsubsection{Interviewees' Diagnosis of Auditable Systems}

Recognized companies have gotten the authority to audit the cargo vessels. Many of the interviewed seafarers label this as the reason for the extensive safety management systems and the intense focus on them. One interviewee blames the Maritime Authority for giving such a responsibility to private organizations.

It's the Maritime Authority's fault. They gave all of the ISM to the recognized companies. They love it! Every non-conformity gives income.

\section{Captain, general cargo vessel}

Large ship-owning companies have office personnel that specializes their safety management systems to the auditors, to get as few non-conformities as possible. Seafarers in smaller companies call these safety management professionals "the cut-and-paste people". An interviewee uses a metaphor to illustrate that many safety management systems primarily are made to be auditable:

It's easy for the company to get no non-conformities, and follow what's to be followed. So [the system] won't be adjusted. Just buy the service and get it over with. [ ... ] You bring apples to school for the teacher to be satisfied, but you don't get full yourself. It doesn't help yourself.

Mate, fodder vessel

This indicates that it may not be common to use company-specific knowledge to make safety management systems specialized for their activity. Rather, many of the interviewed seafarers make clear that their safety management systems are made to work only formally to be approved in audits. One captain says that their procedures "certainly do not increase safety on the workplace". He believes the ISM Code opens for systems that document the actual work, but that the regulations still have been interpreted otherwise:

What we did in our daily business was going to be documented. But it's grown so crazy. The largest problem is the possibility for interpretations-it's like reading the Bible. And there's a new meaning every time a new auditor comes. [ . . ] If we're to increase safety, we have to remove the possibility for companies to [financially] profit on safety. Like [consultants], that thrives on safety. That's the problem with ISM. It's become business, rather than a resource for safety.

Captain, general cargo vessel

\subsection{Survey Results on the Relationship between Procedure Negligence and Safety Outcomes}

Table 4 shows bivariate Pearson's $r$ correlations between the "Procedure negligence index" and different safety outcomes.

Table 4. Pearson's r correlations between the 'procedure negligence index' and different safety outcomes.

\begin{tabular}{cc}
\hline Safety Outcomes & Correlation \\
\hline Personal injuries in the last two years & $0.220^{* * *}$ \\
Ship accidents in the last two years & 0.095 \\
Worry about risk on board & $0.279^{* * *}$ \\
Safety assessment of work place situation & $-0.498^{* * *}$ \\
\hline \multicolumn{2}{c}{$p<0.1{ }^{* *} p<0.05 .{ }^{* * *} p<0.01}$.
\end{tabular}

Three of the correlations in Table 4 are significant at the 0.01 level. Interestingly, we see a weak relationship between respondents' personal injuries in the last two years and the 'procedure negligence 
index'. The same applies for the 'worry about the risk on board' variable. The strongest relationship in the table is between the 'procedure negligence index' and respondents' assessment of the safety of their work place situation. This relationship is moderate and negative, indicating that respondents who report of more procedure negligence tend to give lower assessments of the safety of their work place situations. Finally, the relationship between ship accidents in the last two years is not statistically significant.

\subsection{Suggestions on How to Close the Gap between Formal and Informal Safety Management}

This section consists of the interview results about how formal procedures could become relevant as safety management in practice.

\subsubsection{Reduction of Work Pressure}

Work pressure in the cargo industry stems especially from efficiency demands. The seafarers experience a pressure to work fast, sometimes under risky circumstances, to continue to be in business. The narrow time margins in the schedules limit the seafarers' possibility to rest and work safely. Only when business is going slow, they have time to follow all safety procedures. Most of the seafarers see no solution to the efficiency demands as the industry works now. However, many dream that the government would demand more manning and long enough resting periods for vessels of all flags. This would make fair competition, contrary to the present situation.

Then the government has to come in and regulate how it should be. And everyone would have to comply. Then everyone would be equal, right.

Captain, dry cargo vessel

For some, work pressure has decreased with new technology. Technology has made it possible to rest and work safely within the existing time schedules. Better vessels and equipment for loading and discharging on board, including remote controls to open the customers' hatches, has led to easier and better planned operations, resulting in more safety for the seafarers:

On one of the former vessels I drove a digger. It was stressful to sit there and hear the ropes start breaking, and then have to run from the digger to the bridge [to navigate the loose vessel into safety]. Now we all work inside, dry, and almost always with coffee in our mugs.

Mate, fodder vessel

\subsubsection{Improving Formal Procedures}

The concept of safety management systems functions as a nave in the safety regulation. The qualitative data in this study propose that the coastal cargo seafarers in Norway work to avoid encounter with the procedures virtually as much as they work to avoid accidents. On the positive side, the interviewees have many suggestions on how to improve procedures: A solution indicated by everyone is practical safety management systems. This is seen as obtainable as long as the systems are developed by the users, continuously improved, simplified, and supervised by local expertise instead of general experts, as will be described in this section. The last part of this section presents characteristics of the live fish carriers and a successful safety management system.

\subsubsection{Made by the Practitioners for the Right Activities}

A wish from many of the interviewed ship officers is a safety management system made entirely for their vessel. When the procedures are made for the specific operations, also the training will fit with the context. This is seen as especially valuable, since it will help in building knowledge and experience with the procedures, the equipment, and how to prevent accidents and respond in emergency situations. 
The seafarers reckon themselves as the most competent to make a practical safety management system.

I swear that the ones in the field, the ones performing the job, are best fitted to assess the situation and the risk. They must be more involved, get more to say [ ... ].

Mate, fodder vessel

Still, the interviewees reckon that seafarers mostly do not have, or do not get time to develop a complete safety management system, and that many ship-owner companies already have safety management professionals. A suggestion is therefore that they should make the systems, after thorough research about a vessel's activities.

An alternative is that the decision-makers should come out in the field, see how the job's done in practice. Many onshore think that things are like this and that, and when they come out they see that it's not like that at all.

Mate, fodder vessel

Anyway, pre-made safety management systems are believed to be common also in the years to come. Developing a safety management system demands knowledge about the ISM Code, the vessel activity, and the auditing process, as well as resources to do a thorough job. The ship officers acknowledge that it might be difficult for the small ship-owning companies to build a system from scratch. Now, many of the described safety management systems are made for larger vessels with other operations and equipment, resulting in procedure violations due to necessary local adaption. In the interviews, it is evident that the seafarers believe that their company will continue to buy safety management systems as a standard commodity. The ship officers that have reflected about it recommend that the systems should be adjusted to their local context before they are implemented on a vessel.

\subsubsection{Make Changes along the Way}

During use, the practitioners find requirements that do not match the equipment and the operations. The seafarers advise to update the safety management system continuously in the light of practical experiences.

When we get the system on board it's often written for another vessel. It's the same about the procedures. So, we get a job to do, to get the procedures to correspond with reality. [... ] Adjust the system to vessel, equipment and manning. So, the map and the terrain match. [... ] We do that onboard, we send feedback to the company and point out that this is nothing we can be acquainted with, because it isn't correct.

Mate, fodder vessel

\subsubsection{Simplify}

Another important part of creating a practical safety management system is simplicity. According to the interviews, one should focus on simplification when developing or adjusting the system. Only what is relevant for the vessel and its actual operations should be a part of the system. The procedures should be as short as possible, including only necessities. The most important documents should be easy to find, and not "drowned" in other paper or files. If it is problematic to simplify the system adequately, the seafarers suggest highlighting the most important procedures. These can be presented in a more practical way for the practitioners.

On my last vessel I made a safety manual, where I extracted what they need to follow on a daily basis-work procedures and risk considerations - a small binder that was supposed 
to be easy to get familiarized with. I don't know if it worked, but at least it got more interest than the ugly large ISM binder.

Mate, bulk vessel

A recommendation almost every one of the interviewed ship officers stressed is that common sense is the most valuable safety procedures. Good procedures leave room for the practitioner to think for her-/himself, and act practically and responsibly:

It's okay to have the ISM [safety management system] as a guide, but it's also something about using your head and think rationally outside what's written. It's not always that what's written is very rational.

Captain, bulk vessel

\subsubsection{In-House Competence Auditing}

The safety management systems must go through periodically internal and external revisions. In Norwegian coastal cargo transport most of the ship-owners companies are small, with a one or a few vessels and none or one person in the onshore management. These small companies usually buy auditing services from consultant companies. This is also common among the ship-owner companies with several vessels and some office staff. One of the interviewees represents a ship-owner company that have internal personnel that makes in depth follow-up of procedures revision and negligence. He suggests that smaller companies can cooperate to hire an 'in-house' person to do internal audits and make a system that can be both practical and auditable.

If you're a small company and outsource your ISM. It doesn't give our kind of follow-up. [ ... ] If they could be together, several companies, and hired someone to be responsible for it. You could get a consultant, from DNV or someone, but that won't be follow-up, you'll get a new guy everytime.

Management, bulk vessel company

\subsubsection{Lessons from an Aligned Safety Management System}

In this study, one interviewee was clearly most satisfied with his company's safety management system. This was the interviewed mate on a modern live fish carrier, who described almost no gap between formal and informal aspects of safety on his vessel.

Many of the success factors of this system can be seen as advice for other ship-owner companies, as the organizational conditions can be replicated. The procedures were made specifically for each vessel, with practitioners, and with a detail level which made the procedures simple, but still helpful in difficult operations. Within the organization, a feeling was created that everyone can contribute to improvements of the system and procedures-and the seafarers do come with recommendations for change.

However, there are reasons to believe that some of the success stems from characteristics with the live fish carrier, and is difficult to replicate in other sectors. For example, the complexity of the aquaculture industry makes many operations so advanced and variable that the practitioners need to look up the procedures to proceed with the operations. It also seems to be relevant that the manning on the live fish carriers are familiar with formal procedures and technology, and that competence about this is important for their identity.

\section{Concluding Discussion}

Previous studies from the coastal cargo sector report of a considerable gap between formal and informal aspects of safety, and maritime accident investigations report that this gap may be an important contributory cause (e.g., [3]). The main aims of this paper were therefore to examine the 
factors influencing procedure negligence, and to discuss how to reduce the gap between formal and informal aspects of safety.

\subsection{Factors Influencing Procedure Negligence}

Our results indicate that a high score of procedure negligence may be a symptom of a discrepancy between formal and informal aspects of safety. When formal procedures are not followed, they may be replaced by informal routines. Interviewees said that most of the work is done safely and according to procedures, but they also commented that procedures are neglected on a daily basis, mostly because: (a) procedures do not fit the situation, (b) the vessel does not have either the time or (c) manning to comply, (d) because the seafarers do not know the procedure, or (e) because of unintentional slips. These results are in accordance with previous research $[6,9,27,30,31]$. Procedure negligence has several causes, as our quantitative and qualitative data elaborates on.

First, work pressure and demanding working conditions seem to be important factors making the seafarers ignore or violate procedures. The survey results indicate that work pressure is the variable with the strongest contribution to procedure negligence, followed by demanding working conditions. The interviewees implicitly and explicitly contrasted the formal 'paper work' procedures, focusing on accountability and documentation, with the informal routines or culture of 'getting the job done'. Some interviewees said, for instance, that they almost never have the time to do both the risk analysis and the work operation. Størkersen et al. [9] also referred to "sleeping rules" as one of the main findings of their study, meaning that some rules collectively are followed on board while other are ignored. Our interviewees primarily related the discrepancy between formal and informal aspects of safety to efficiency demands, tight economic margins, and competition, as they asserted that complying with the formal preparations would take them too long and make them come behind their schedule. This is in line with the survey results, and with previous research (cf. [9]). The work pressure is a mix of conditions stemming from employers, customers, the industry, and also the seafarers themselves. The coastal cargo companies are in competition with other types of transportation, with each other and with vessels of different flags/conditions. Moreover, some interviewees also complained that transport buyers focus more on price rates than safety.

Second, interview data indicate that the perceived usefulness of the procedures may explain why the paper work is sometimes skipped. It was suggested that many of the described safety management systems are made for larger vessels with other operations and equipment, resulting in procedure negligence due to necessary local adaption. This is in accordance with previous research from the maritime sector $[6,27,30,31]$.

Third, seafarers' professional identity may be important in their understanding of procedure compliance. Interviewees said doing a good job involves working as safe as possible while at the same time being efficient. Their perceived work pressure is also attributed to themselves; as they take responsibility for their company to stay in business and them to keep their job. Seafarers relatively often deal with situations involving competing demands, 'grey areas' (e.g., situations of challenging weather conditions), and professional judgment. Interview results indicate that these considerations are closely related to their professional identity. We also saw that interviewees to some extent asserted that the seafarer culture involves accepting little rest at times and that they had to 'chip in' whenever needed. Moreover, they also contrasted themselves to former offshore workers, who are "unable to do anything without using checklists". Such a contrast between professional identity and formal safety management systems has also been noted in previous research (for example $[6,30,31]$ ). Other studies report employee resistance in an early procedure implementation phase, as seafarers felt that their professional pride was discredited $[5,6,30]$. The interview results do, however, not indicate that this is a main factor related to interviewees' attitude to the formal systems. It may rather be a symptom than a cause. Rather, lacking use of procedures was mostly related to getting the job done within schedule and the perception that the SMS was poorly adapted to the work activities on board. 
Significantly, our survey also indicates that a positive organizational safety culture is related to less procedure negligence. Previous research indicates that procedure negligence may be an indication of a poor safety culture [3]. A poor safety culture has been explained as involving a considerable discrepancy between the formal procedures of 'how things should be done', and the way that things are actually done. It seems that vessels with a strong focus on safety among leading officers and crew members (i.e., good safety culture) in general have fewer violations and less sleeping rules. Among the interviewees some, have experience of consistency between formal and informal safety management. They report procedures made for their activities, focusing on the right level of detail, reporting that this makes the procedures useful for them to work safely. This is also how all our interviewees described their desired safety management system.

\subsection{How to Reduce the Discrepancy between Formal and Informal Safety Management?}

Ideally, informal aspects of safety should be aligned with the formal safety management. In other words: the "way things are actually done" should correspond with the "way things should be done" according to formal procedures. An established reason is that safety structure, e.g., standardization through training, procedures and goals, may be an important way of achieving control, coordination and subsequently organizational safety (cf. $[8,20])$.

In this study, the context is described as a main reason for the discrepancy: work pressure, competition and economic framework conditions. Interviewees asserted that universal rules about manning and rest and perhaps new technology could improve the situation. Given that it may be difficult to change international rules and the context, it seems that the most important factor to address is the perceived applicability of the procedures.

How procedures are perceived to be useful is related to how they are adapted to the vessels. In line with the research of e.g., Lappalainen et al. [5], the present paper indicates that the quality of the formal safety system influences the alignment between formal and informal aspects of safety. Interviewees suggested that many of the described safety management systems are made for larger vessels with other operations, resulting in procedure violations due to necessary local adaption. Interviewees suggest that formal and informal aspects of safety would be aligned if the procedures were practical. The procedures could be practical if they were: (1) developed by the users, (2) continuously improved, (3) simplified and (4) supervised by local auditors. Even though we have seen examples of aligned formal and informal aspects of safety, and the interviewed seafarers have a clear recipe for good quality procedures, previous literature has shown this is difficult to achieve, especially because of the auditability demand [32]. Future research should look more into how shipping companies could achieve this.

When things are done in other ways than formally described, it has in some cases been referred to as a "poor safety culture". This relationship is however complex, as there may be good reasons why procedures are violated or ignored. There may be too many procedures, they may be complex, inappropriate, poorly adapted etc. This is indicated in our interview data, as well as in previous research, for example [27-29,32]. Procedures may in some instances also have been implemented with the objective to be found flawless by any auditor, rather than to be found relevant and practical by the crew [32]. As the interviews indicate, formal safety management systems may become standardized and complex with more procedures and reporting than necessary, resulting in bureaucracy that marginalize practical safety work [27-29,32] and leave seafarers to avoid regulation [6,30,31]. In such instances, informal appropriate safety routines may be needed to compensate for unsatisfactory procedures. Most interviewees underlined that "common sense" is the most valuable safety measure. Thus, the informal safety culture may also compensate for poorly adapted or inappropriate formal procedures. More research is needed to shed light on these important issues.

Survey results indicate that procedure negligence is correlated with personal injuries and perceptions of risk and safety. Fortunately, the number of personnel accidents has decreased in the maritime sector in recent years (e.g., [3,6,32]). Størkersen et al. [6] and Størkersen [32] discuss 
how parts of this development can be attributed to formalized safety measures. Mandatory safety management makes companies invest in safety measures and routines. Some of the positive sides of having safety procedures are information and reflections about risks and safety measures. This has the potential to increase safety in operations (decrease personal injuries). However, spending time on documentation and adjusting inappropriate formal procedures to practice, might lead to negative safety outcomes $[28,29,32]$. It is evident how important it is to make sure formal procedures can be used in practice. This underlines how important it is for the formal and informal safety routines to match.

\subsection{Methodological Weaknesses and Questions for Future Research}

In this study, we have combined different sources of data, many of them which have considerable limitations. The survey data is based on a limited sample, dominated by a subsector within Norwegian maritime transport (coastal cargo). The qualitative interview sample is based on a low number of interviewees, and thus the qualitative results may be termed preliminary. Saturation is often defined as the point where the interviewing researcher perceives that further interviews are not required, as he or she sees similar instances "over and over again", justifying e.g., the creation of analytical categories or theoretical concepts (cf. Glaser and Strauss in [33]). Collecting qualitative data for the present study, the interviewing researcher perceived that the results we describe based on the interviews represent patterns that were recurring in the interviews (indicating saturation). Nevertheless, the interview data is based on a limited number of people, and it cannot be used to draw solid conclusions, but to illuminate possible relationships and questions to be examined in future research. We also draw on previous research, and it should be noted that some of the key interview results are in accordance with results from previous research conducted in the same sector, both in Norway (cf. [32]), and in other countries (e.g., [34,35]).

Based on these three sources of data (survey, interviews, previous research), our study suggests that the relationships illuminated in the figure should be examined in future research. It is important to note that the figure merely depicts hypothesized relationships, based on the data analyzed in the present study.

Previous research indicates that a discrepancy between formal and informal aspects of safety may have both individual and organizational causes. It is unfortunately difficult to use the survey results to draw conclusions about the relative importance of these factors. Results from the regression model suggest, however, that the organizational factors (work pressure, demanding working conditions, safety culture) explain nearly half of the variation in the procedure negligence index (the Adjusted $R^{2}$ value is 0.468 ). In the interviews, these organizational factors were related to framework conditions, as indicated in Figure 1. We may hypothesize that individual factors may be included among the factors influencing the remaining unmeasured half of the variation in the dependent variable, and suggest that future research should develop research designs to evaluate the significance of individual versus organisational causes of procedure negligence. 


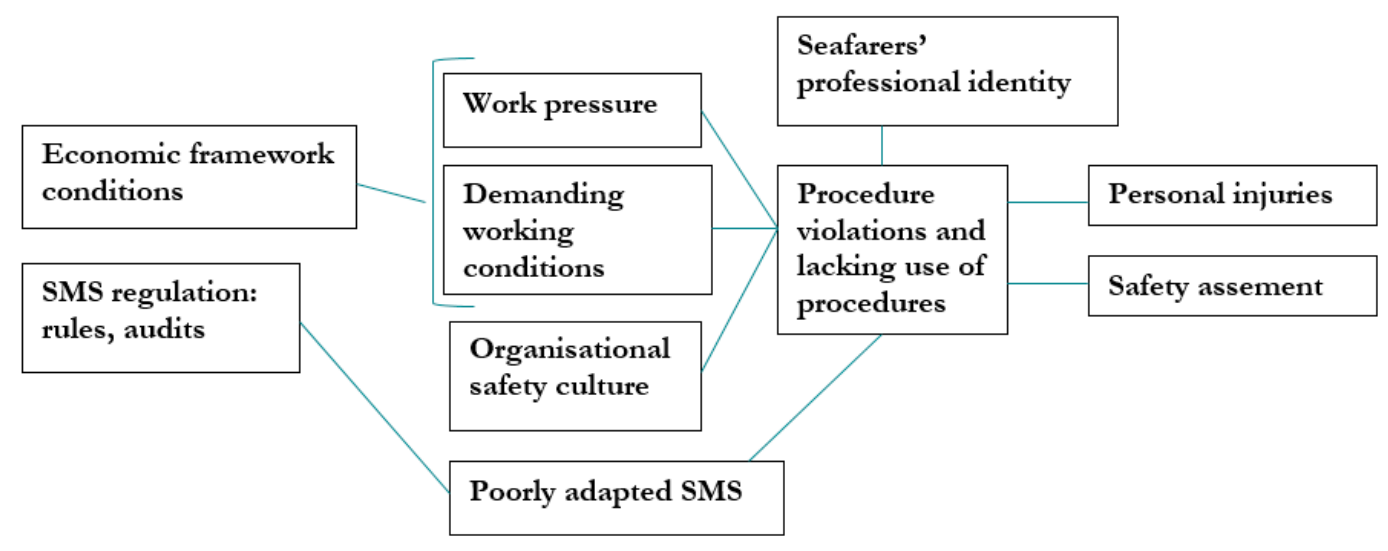

Figure 1. Hypothesized relationships, based on the quantitative and qualitative data analyzed in the present study.

\subsection{Finalizing Remarks}

Earlier research in the cargo sector and numerous accident investigations from other sectors point to a discrepancy between formal and informal aspects of safety to explain why accidents come about (cf. $[3,11])$. It is therefore important to discuss how the factors contributing to a discrepancy between formal and informal aspects of safety can be reduced. This study's qualitative and quantitative data indicate that the gap may be related to work pressure and working and framework conditions, as well as procedure adaption. When formal procedures are of low quality, they are less likely to be used. Our survey results also indicate that procedure negligence is related to outcome measures like personal injuries and perceptions of risk and safety. A positive organizational safety culture is experienced by respondents reporting of less procedure negligence. It is suggested that the discrepancy between formal and informal safety management to some extent can be reduced through practical vessel-specific procedures.

Author Contributions: Conceptualization: T.-O.N., K.V.S. and R.O.P.; Methodology, T.-O.N., K.V.S., and R.O.P.; Formal Analysis: T.-O.N; Investigation: T.-O.N. and K.V.S.; Data Curation, T.-O.N. and K.V.S.; Writing-Original Draft Preparation: T.-O.N., K.V.S., and R.O.P; Writing-Review and Editing: T.-O.N. and K.V.S.; Visualization: T.-O.N.; Supervision: T.-O.N.; Project Administration: T.-O.N.; Funding Acquisition: T.-O.N.

Funding: This research was funded by the Norwegian Research Council's Transikk program, grant number 236643.

Acknowledgments: We are grateful to the Norwegian Research Council's Transikk program for funding this research. We would also like to thank the interviewees and the respondents for participating in our study.

Conflicts of Interest: The authors declare no conflict of interest. The funding sponsors had no role in the design of the study; in the collection, analyses, or interpretation of data; in the writing of the manuscript, or in the decision to publish the results.

\section{Appendix A. Survey Measures}

The survey included a total of 80 questions on the following themes. See Nævestad [12-14] for a presentation of the other survey questions, themes, and results. Many of the survey questions are from the study of Størkersen et al. [9]. Additionally, many of the questions are based on a questionnaire developed by Safetec for The Norwegian Maritime Authority.

\section{Appendix A.1. Background Variables}

The following background variables are included: safarers' position/line of work (one item), seafarers' age (one item), seafarers' experience (one item), vessel type (one item), vessel age (one item), vessel registry (one item). 
Appendix A.2. Procedure Violations, Sleeping Rules, and Lacking Use of Procedures

The survey includes three questions on procedure negligence:

- Violation of procedures seldom has consequences

- The competition between shipping companies means that we sometimes have to violate safety procedures

- I never use written procedures in the work I perform on board

We constructed an index summing up these three items. The index has a Cronbach's Alpha $=0.626$, which ideally should have been higher. We nevertheless choose to keep this index, despite the relatively low score for two reasons. First, the index is comprised of only three questions, which makes it more difficult to attain a high Cronbach Alpha score. Second, the index provides a multifaceted measure of what we want to measure: procedure negligence. Additionally, the index refers to whether crewmembers use procedures themselves ('individual behavior level'), whether they and their colleagues ('crew behaviour level') have to violate rules because of competition, and whether violations have consequences ('ship management level'). As the index includes these three different levels-(a) individual, (b) crew, and (c) ship management—it provides a robust and comprehensive measure of procedure negligence on board.

\section{Appendix A.3. Organizational Safety Culture}

We made an organizational culture index, based on the GAIN-Scale on organizational safety culture, (cf. the "Operator's Safety Handbook" [36]). GAIN is an acronym for the 'Global Aviation Information Network', which is a voluntary association of airlines, manufacturers, trade unions, governments and other organizations in aviation. Although the GAIN questionnaire originally was developed for the aviation sector, we used it as it focuses on aspects of culture which have been found to be crucial in previous research: e.g., management and employee commitment to safety (e.g., [17]), a reporting and learning culture (e.g., [37]), safety training and safety communication [38]. We have used this scale in our previous research, examining safety culture in several different transport sectors $[39,40]$.

As our original survey included a high number (80) of questions (cf. [12]), we chose to reduce the original GAIN questions measuring organizational safety culture from 25 to 18 . When selecting these 18 questions, we focused on questions that we previously found to generate statistically significant differences between companies (e.g., [40]). Results indicate that these generally are the most specific questions, referring to concrete functions and situations. We may therefore hypothesize that the concrete questions (e.g., "Management often praises crew members who work safely") work better as indicators of specific dissimilarities among the companies than the more general and abstract questions (e.g., "Managers do all they can to prevent accidents").

The safety culture index is computed as the sum of the scores of the 18 questions (Cronbach's Alpha $=0.950$ ), and these 18 questions are answered using a scale from 1 (disagree completely) to 5 (agree completely). Consequentially, our applied version of the GAIN index for organizational safety culture has a minimum score of 18 and a maximum score of 90 . The scale is based on five themes. Although we do not focus on the results for each theme, we list each theme and the questions that they are comprised of in the following:

(Ia) Shipping company commitment to safety

- The shipping company regards safety to be a very important part of all work activities

- The shipping company is aware of the most important safety problems that we have on board

(Ib) Ship management commitment to safety

Because seafarers relate to both the ship management on board and management and personnel in the shipping company ashore, we also ask the two above mentioned questions about the ship 
management, in addition to three other questions on ship management commitment to safety (which makes a total of five questions about ship management commitment to safety):

- Ship management regards safety to be a very important part of all work activities

- Ship management is aware of the most important safety problems that we have on board

- Ship management stops unsafe operations and activities

- Ship management detects crew members who work unsafely

- Ship management often praises crew members who work safely

(II) Employee commitment to safety

- My colleagues on board usually report all safety problems and unsafe situations that they experience in their work

- My colleagues on board do all they can to prevent accidents and unwanted incidents

(III) Reporting culture

- There are routines (procedures) on board for reporting safety problems

- All defects or hazards that are reported are corrected promptly

- After an accident has occurred, appropriate actions are usually taken to reduce the chance of reoccurrence

- Everyone has sufficient opportunity to make suggestions regarding safety

(IV) Safety training

- All crew members on board receive adequate training to work in a safe way

- All newly employed are provided with sufficient training for their work activities

- Everyone on board is kept informed of any changes which may affect safety

(V) General safety questions

- Safety on board is generally well controlled

- Safety on board this vessel is better than on other vessels

Appendix A.4. Working Conditions

The following questions about working conditions are included in the study: manning level, port calls, work pressure, demanding working conditions, and safety compromising fatigue. These questions were included as previous research has showed differences between crews on Norwegian vessels on these factors, and as research indicates that these factors influence ship safety and occupational safety on board Norwegian vessels [9].

Manning level on vessels

- Please specify total manning on board the vessel

Work pressure

- Sometimes I feel pressured to continue working, even if it is not perfectly safe

Port calls

- Number of port calls per week

Demanding working conditions. (index summing up three items). (Cronbach's Alpha $=0.780$ )

How often do you think that the following events happen while you are at sea? 
- Your shift change is delayed because of work operations, for instance port calls?

- You work more than $16 \mathrm{~h}$ in the course of a $24 \mathrm{~h}$ period?

- You are interrupted when you are off duty?

The respondents answered these three questions using a scale from 1 (never) to 7 (daily when I am at sea). The demanding working conditions index is computed as the sum of the scores of the three questions. This gives a minimum score of 3 and a maximum score of 21.

\section{Appendix A.5. Safety Outcomes}

The survey includes four measures of safety outcomes:

- Have you been injured in your work on board in the course of the last two years?

- Has the vessel been involved in a shipping accident (e.g., grounding, collision, contact injury, fire) in the two last years?

- To what extent do you worry about risk aboard?

- All in all, how do you assess the safety of your work place situation?

\section{References}

1. Alderton, T.; Winchester, N. Globalisation and de-regulation in the maritime industry. Mar. Policy 2002, 26, 35-43. [CrossRef]

2. Oldenburg, M.; Jensen, H.J. Merchant seafaring: A changing and hazardous occupation. Occup. Environ. Med. 2012, 69, 685-688. [CrossRef] [PubMed]

3. Nævestad, T.-O.; Phillips, R.O.; Elvebakk, B.; Bye, R.J.; Antonsen, S. Work-Related Accidents in Road Sea and Air Transport: Prevalence and Risk Factors; TØI Report 1428/2015; Transportøkonomisk Institutt: Oslo, Norway, 2015.

4. European Maritime Safety Agency (EMSA). European Statistics from the European Maritime Safety Agency; EMSA: Lisbon, Portugal, 2014.

5. Lappalainen, F.J; Kuronen, J.; Tapaninen, U. Evaluation of the ISM Code in the Finnish shipping companies. J. Marit. Res. 2014, 9, 23-32.

6. Kongsvik, T.; Gjøsund, G. HSE culture in the petroleum industry: Lost in translation? Saf. Sci. 2016, 81, 81-89. [CrossRef]

7. Ek Å Runefors, M.; Borell, J. Relationships between safety culture aspects—A work process to enable interpretation. Mar. Policy 2014, 44, 179-186.

8. Thomas, M.J.W. A Systematic Review of the Effectiveness of Safety Management Systems; No. AR-2011-148; Australian Transport Safety Bureau: Canberra, Australia, 2012.

9. Størkersen, K.V.; Bye, R.J.; Røyrvik, J.O.D. Sikkerhet i fraktefarten. Analyse av drifts- og arbeidsmessige forhold på fraktefartøy. In NTNU Samfunnsforskning AS; Studio Apertura: Trondheim, Norway, 2011.

10. Antonsen, S. The relationship between culture and safety on offshore supply vessels. Saf. Sci. 2009, 47, 1118-1128. [CrossRef]

11. Nævestad, T.-O. Cultures, Crises and Campaigns: Examining the Role of Safety Culture in the Management of Hazards in a High Risk Industry. Ph.D. Dissertation, University of Oslo, Oslo, Norway, 2010.

12. Nævestad, T.-O. Safety in Maritime Transport: Is Flag State Important in an International Sector? TØI-Rapport 1500/2016; Transportøkonomisk Institutt: Oslo, Norway, 2016.

13. Nævestad, T.-O. Occupational Safety and Work-Related Factors in Norwegian Maritime Transport; TØI Rapport 1501/2016; Transportøkonomisk Institutt: Oslo, Norway, 2016.

14. Nævestad, T.-O. Safety culture, working conditions and personal injuries in Norwegian maritime transport. Mar. Policy 2017, 84, 251-262. [CrossRef]

15. Hale, A. Editorial: Culture's Confusions. Saf. Sci. 2000, 34, 1-14. [CrossRef]

16. Cox, S.J.; Flin, R. Safety Culture: Philopher's Stone or a Man of Straw? Work Stress 1998, 12, 189. [CrossRef]

17. Zohar, D. Safety climate: Conceptualization, measurement, and improvement. In Oxford Handbook of Organizational Climate and Culture; Oxford University Press: Oxford, GB, 2014; pp. 317-334. 
18. Guldenmund, F.W. The Nature of Safety Culture: A Review of Theory and Research. Saf. Sci. 2000, 34, 215-257. [CrossRef]

19. Pidgeon, N.; O’Leary, M. Man-Made Disasters: Why technology and organisations (sometimes) fail. Saf. Sci. 2000, 34, 15-30. [CrossRef]

20. McShane, S.L.; Travaglione, A. Organizational Behaviour on the Pacific Rim; McGraw-Hill Higher Education: Sydney, Australia, 2003.

21. Snook, S.A. Friendly Fire: The Accidental Shootdown of U.S. Black Hawks over Northern Iraq; Princeton University Press: Princeton, NJ, USA, 2000.

22. Reason, J. Human error: Models and management. Br. Med. J. 2000, 320, 768-770. [CrossRef]

23. Mostad, L.T. Håndtering av Målkonflikter I Bøyelast: ET Casestudie av Hvordan Rederi og Oljeselskap Tilrettelegger for at Sikkerhet kan Prioriteres av Ledende Offiserer Ombord PÅ Bøyelastere. Master's Thesis, Senter for Teknologi, Innovasjon og Kultur, Universitetet i Oslo, Oslo, Norway, 2009.

24. Perrow, C. Normal Accidents: Living with High-Risk Technologies; Princeton University Press: Princeton, NJ, USA, 1999.

25. Reason, J. Managing the Risk of Organisational Accidents; Ashgate: Aldershot, UK, 1997.

26. Fourie, C.; Holmes, A.; Hildritch, C.; Bourgeois-Bougrine, S.; Jackson, P. Interviews with Operators, Regulators and Researchers with Experience of Implementing Fatigue Risk Management Systems; Road Safety Research Report; Department for Transport: London, UK, 2010.

27. Almklov, P.G.; Rosness, R.; Størkersen, K.; Almklov, P.G.; Rosness, R.; Størkersen, K. When safety science meets the practitioners: Does safety science contribute to marginalization of practical knowledge? Saf. Sci. 2014, 67, 25-36. [CrossRef]

28. Bieder, C.; Bourrier, M. Trapping Safety into Rules: How Desirable or Avoidable Is Proceduralization? Ashgate: Farnnham, UK, 2013.

29. Dekker, S. The bureaucratization of safety. Saf. Sci. 2014, 70, 348-357. [CrossRef]

30. Vandeskog, B. The Legitimacy of Safety Management Systems in the Minds of Norwegian Seafarers. TransNav Int. J. Mar Navig. Saf. Sea Transp. 2015, 9, 101-106. [CrossRef]

31. Knudsen, F. Paperwork at the service of safety? Workers' reluctance against written procedures exemplified by the concept of 'seamanship'. Saf. Sci. 2009, 47, 295-303. [CrossRef]

32. Størkersen, K.V. Bureaucracy Overload Calling for Audit Implosion A Sociological Study of how the International Safety Management Code Affects Norwegian Coastal Transport. Ph.D. Thesis, Norwegian University of Science, Trondheim, Norway, 2018.

33. Saunders, B.; Sim, J.; Kingstone, T.; Baker, S.; Waterfield, J.; Bartlam, B.; Burroughs, H.; Jinks, C. Saturation in qualitative research: Exploring its conceptualization and operationalization. Qual. Quant. 2017, 52, 1893-1907. [CrossRef] [PubMed]

34. Smith, A.P.; Lane, T.; Bloor, M.; Allen, P.H.; Burke, A.; Ellis, N. Fatigue Offshore: Phase 2 The Short Sea and Coastal Shipping Industry; Seafarers International Research Centre/Centre for Occupational and Health Psychology, Cardiff University: Cardiff, Wales, 2003.

35. Starren, A.; van Hooff, M.; Houtman, I.; Buys, N.; Rost-Ernst, A.; Groenhuis, S.; Dawson, D. Preventing and Managing Fatigue in the Shipping Industry TNO-Report 031.10575; TNO: Hoofddorp, The Netherlands, 2008.

36. GAIN. "Operator's Safety Handbook". 2001. Available online: https://flightsafety.org/wp-content/ uploads/2016/09/OFSH_english.pdf (accessed on 10 August 2018).

37. Reason, J. Achieving a safe culture: Theory and practice. Work Stress 1998, 12, 293-306. [CrossRef]

38. Edkins, G.D. The INDICATE safety program: Evaluation of a method to proactively improve airline safety performance. Saf. Sci. 1998, 30, 275-295. [CrossRef]

39. Bjørnskau, T.; Longva, F. Torkel Bjørnskau, Frode Longva, Sikkerhetskultur i Transport; TØI Rapport 1012/2009 Oslo; Transportøkonomisk Institutt: Oslo, Norway, 2009.

40. Nævestad, T.-O.; Bjørnskau, T. Kartlegging av Sikkerhetskultur i tre Godstransportbedrifter; TØI Rapport 1300/2014; Transportøkonomisk Institutt: Oslo, Norway, 2014.

(C) 2018 by the authors. Licensee MDPI, Basel, Switzerland. This article is an open access article distributed under the terms and conditions of the Creative Commons Attribution (CC BY) license (http://creativecommons.org/licenses/by/4.0/). 